\title{
POR DETRÁS DO PALCO: A FIGURA FEMININA NAS CANTIGAS DE AMIGO
}

Olga Coval é doutoranda em Literatura de Língua Portuguesa na Faculdade de Letras da Universidade de Coimbra E-mail: ocoval@sapo.pt

\author{
Resumo \\ O objectivo deste artigo é reflectir acerca da \\ importância da figura feminina nas cantigas de \\ amigo trovadorescas. Tendo em conta que a \\ mulher não tinha voz literária na época \\ medieval, questionamos as relações entre os \\ géneros nestes poemas, composições que se \\ assumem simultaneamente como jogos de \\ linguagem e de poder.
}

\begin{abstract}
The intention of this article is to consider about the importance of the female character in the troubadours cantigas de amigo. Considering that women had no literary voice in the medieval ages, we question about the gender relationships in these poems, compositions that assume themselves simultaneously as language and as power games.
\end{abstract}

A figura feminina ocupa um espaço central nas cantigas de amigo, quer como elemento de enunciação, quer como personagem principal ou foco de interesse à volta do qual se constroem as composições.

Como é sabido, de meras humanas a heroínas ou deusas, as mulheres povoam a literatura desde os seus primórdios. Através dela ecoam os murmúrios da beleza de Helena, da perseverança de Penélope, da curiosidade de Pandora, da determinação de Lisístrata, da trágica paixão de Dido, entre outras, inolvidáveis. Ao longo da História, porém, poucas foram as que em voz própria legaram as suas memórias, impressões ou vivências. Safo ou Sulpícia, escritoras da Antiguidade Clássica, ou Santa Hildegarda, mística da Idade Média, são alguns dos vultos femininos que representam a escassez de mulheres autoras em épocas recuadas. Numa mundividência em que o poder, num âmbito geral - embora com algumas exceções -, se confinava a uma égide masculina e só no final do século XIX teve em consideração o sufrágio feminino, não nos surpreende esta ausência no panorama da criação literária. A elevada taxa de analfabetismo que, mesmo sem dados precisos, depreendemos afetar maioritariamente este género deverá ter contribuído para esta segregação na época medieval:

Ao avaliar os poucos testemunhos literários que nos ficaram, algumas trobairitz, um autor de lais no final do século XIII e mais tarde as figuras mais seguras de si mesmas, na aurora do humanismo, Cristina de Pisano e, na sociedade italiana, essas letradas que não solicitam senão poder tomar a palavra, adivinha-se, sabe-se mesmo que o acesso da mulher à expressão é difícil. E se o dizer das místicas suscita rapidamente a suspeita de um abuso e de heresia, as obras de ficção, por sua vez, na sua ligeireza aparente, indicam que há por vezes transgressão de um domínio que o homem reserva para si. (DUBY, 1990, p.525).

Não obstante esta omissão, a presença da mulher impõe-se na maioria das obras literárias através de uma focalização indirecta, como elemento constante e, muitas vezes, central ou imprescindível. Qual seria pois a intencionalidade de conceder a voz à mulher nas cantigas de amigo? Haveria um propósito encoberto? Apenas podemos especular acerca daquilo que terá levado trovadores e jograis segréis a transferir a propriedade de emissão do seu canto ao mundo feminino. Talvez para colmatar esse 
silêncio que se fazia sentir desde sempre, talvez para enobrecer e dignificar a mulher como mãe, filha, amante e guardiã do futuro e da espécie, talvez para seduzir o sexo oposto. Ou então nenhuma dessas hipóteses. Talvez se trate apenas de mero artifício retórico. Se uma resposta satisfatória acerca destas questões permanece indecifrável em consequência da distância temporal, podemos, por outro lado, colocar outras manifestamente pertinentes: Quem eram estas mulheres à luz de um mundo concebido pelo sexo oposto? Que percepções nos transmitem os compositores? Aliando texto e contexto, tendo em consideração o quão pouco sabemos sobre o mundo feminino na sociedade da época, é possível registar nas cantigas de amigo sequências semânticas transversais que permitem esboçar o retrato destas vozes silenciosas. A mulher medieval constitui-se como fruto de obsessão ou objecto de culto, não só na literatura de carácter amoroso mas também na de cunho tratadístico, religioso, moral e até jurídico.

Convém esclarecer que a partir do século $\mathrm{X}$ a mentalidade sobre a conceção do feminino vai progredindo no sentido de uma profunda sensibilização acerca do seu estatuto no seio familiar e religioso. Se numa primeira instância a mulher é conotada com Eva - a pecadora que encarna o mal e conduz o Homem para caminhos impróprios -, rapidamente ela se transforma em Maria, com a emergência do culto mariano e a propagação dos mosteiros e das ordens religiosas exclusivamente femininos. A mulher é assim elevada a um estatuto sagrado - o ser que preserva a castidade, que propicia a regeneração da espécie e que protege a sua prole.

Por outro lado, as instituições eclesiásticas, na tentativa de angariarem beneméritos e financiarem as suas obras luxuosas, promovem aquilo que Jacques Le Goff apelida de «terceiro lugar» - o Purgatório -, hipótese de redenção, que convoca, mais do que a penitência pelo arrependimento e pela oração, os donativos que asseguravam uma passagem tranquila à eternidade apregoada ${ }^{1}$. Simultaneamente, e em consonância com estes acontecimentos, destaca-se uma figura bíblica que representa a possibilidade de reencontrar o caminho da fé: Maria Madalena. Esta mulher já não é símbolo da maldade de Eva ou tampouco da pureza virginal de Maria, mas sim a mulher terrena, falível, a pecadora que se pode metamorfosear de objeto de desejo em inspiradora de devoção.

Do nosso ponto de vista, a figura feminina do cancioneiro de amigo posiciona-se e oscila entre estes dois paradigmas: o da virgem casta, símbolo da virtude, e o da mulher que cede ao desejo carnal. Recorde-se que ao contrário da «senhor» das cantigas de amor, esta é uma mulher jovem, disponível para a corte e para o comprometimento. Na cantiga de Pero Viviaez Pois nossas madres van a San Simon, os entes femininos são «as meninhas» ou «moças»; por sua vez, em Johan Garcia de Guilhade surge a designação de «donzelas»; Pedr' Amigo de Sevilha refere-se a uma «fremosa poncela»; e Johan Zorro dá voz a uma mulher que diz conduzir «a dona virgo» ou a «dona d'algo». À semelhança deste, também Airas Nunes e Pero Gonçalvez de Porto Carreiro mencionam nas suas composições uma «virgo». O próprio epíteto de «fremosinha», presente nas cantigas de Afonso Sanchez e Bernal de Bonaval, pode adquirir uma conotação de mocidade.

\footnotetext{
${ }^{1}$ Cf. LE GOFF, 1993.
} 
As evidências levam-nos a crer que se trata de jovens nubentes, pois os casamentos nesta época ocorriam numa fase ainda pubescente para ambos os sexos ${ }^{2}$. Para além desta constatação, podemos também inferir que o tipo de rotina diária ou cenário que nos é apresentado sugere estarmos claramente diante de uma jovem de condição social inferior quando comparada com a mulher nobre das cantigas de amor. Ela é muitas vezes a «pastor» ou aquela que «lava camisas»e, ainda, a que vai à «fonte» ou ao «monte».

Identificada assim a faixa etária e social desta mulher, observemos agora um outro aspecto relevante ao nível da construção textual. Com efeito, ao longo dos textos são frequentemente accionados determinados adjectivos que servem como atributoepíteto da figura feminina: «bon parecer», «bon semelhar», «bon prez», «ben talhada», «bela», «velida», «louçana» e «fremosa» ${ }^{3}$. A estes somam-se alguns casos menos recorrentes, embora também de grande valia, como na cantiga - Amigo, queredes vos $i r ?^{4}$, de D. Dinis, em que o amado apelida a protagonista de «senhor bõa e de prez».

Reconheçamos que o significado destes atributos no quadro do conjunto do cancioneiro de amigo acaba por redundar numa certa relatividade que deriva da sua própria recorrência, como se fosse repetição de uma fórmula lógica e natural e, ao mesmo tempo, dependente do contexto da focalização. Naturalmente, o trovador ou o jogral segrel apaixonados, enquanto autores, projetariam sempre uma imagem de beleza vincada da figura feminina. Por outro lado, estas qualidades quando enunciadas pela mulher são reveladoras de uma consciência da própria beleza e que a torna muitas vezes fria e distante em relação ao amigo. Na cantiga Par Deus amigo nunca eu cuidei ${ }^{5}$, de Johan Perez d' Avoin, a mulher reconhece os seus atributos e não compreende como o amado a trocou por outra («por quen non parece melhor de mi»). Quando a amiga se endereça à mãe ou à confidente utilizando estes vocábulos, o elogio adquire um estatuto de polidez. Este artifício retórico retrata, pois, uma convenção literária bastante disseminada na literatura da Baixa Idade Média (surge também nas narrativas místicas e litúrgicas).

Todavia, há algumas referências esporádicas que aludem a caraterísticas físicas mais específicas e das quais podemos retirar algumas ilações: «os cabelos» aparentam ser longos em Johan Soarez Coelho e em Pero Meogo, por exemplo, pois ora são presos ora permitem fazer tranças; a protagonista de Nuno Fernandez Torneol é «delgada» e a amiga de Johan Garcia de Guilhade alude à beleza dos «olhos verdes». Aliás, esta última excepção, materializada numa menção à cor dos olhos, poderia revelar apenas uma preferência do autor; mas, tendo em conta que é dita pela voz feminina como

\footnotetext{
${ }^{2}$ A existência de uma idade própria para o casamento vem atestada nas leis régias: «A lei civil, e também a canónica, estipulavam uma idade mínima ao casamento. À luz daquela «o minino he de revora de XIIII anos e a minina de XII anos» ou «homem que seja de idade comprida e da idade de XIIII anos», idade a partir da qual se podia ser procurador, receber a cavalaria, casar e ser rei, pois só então seria «adulto e capaz de raciocínio», como se afirma no testamento de D. Sancho I, de 1188». (MATTOSO, 2010, p.110).

${ }^{3}$ Sobre estes atributos Mercedes Brea e Pilar Gradín referem que aparecem «normalmente nas cantigas dialogadas, postas en boca do amigo, da nai, das compañeiras; ou da propia amiga, para dirixirse ás súas semellantes» (BREA e GRADÍN, 1998, p.61).

${ }^{4} B$ 575-576/V 179. COHEN, 2003, p.611.

${ }^{5} B 668 / V$ 271. Idem, p. 155 .
} 
asseveração de bem parecer, não deixa de, por certo, sugerir alguma predileção generalizada por esta cor. Por outro lado, na cantiga Ai frores do meu amigo, de Pae Gomez Charinho, a mulher afirma que tem um «corpo loado», e numa muito reconhecida composição ${ }^{6}$ de Airas Nunes ela é uma «virgo» que entretece as horas de sofrimento fazendo «guirlandas de flores». Já na cantiga de Pero Gomez Barroso Direi verdade, se Deus mi perdon, a amiga constata a sua beleza ao «espelho» e diz que nada tem de agradecer ao amado por ele lhe querer bem, mas antes a Deus, que a fez «fremosa».

Se não podemos através dos textos estereotipar a beleza feminina da época e elaborar um retrato translúcido como o de uma Laura, podemos ao menos afirmar com toda a segurança que a mulher ideal se apresentava de cabelos longos, esguia, de olhos claros e de espírito trabalhador, humilde e pacífico. A mulher que aparece cantando tem usualmente uma voz «manselinha», o que aponta para a valorização de uma certa doçura no trato. Parece ainda haver em reuniões de festa e romaria uma espécie de competição de beleza, como pode atestar o caso da amiga de Martin de Padrozelos, que venceu «o cendal.../de parecer» e que será uma das mais formosas da romaria: «ca, se oje i van tres/fremosas, eu serei/a ũa, ben o sei» - o que nos leva a crer que estas mulheres cuidavam da sua aparência. Aliás, na cantiga Ai mha filha, por Deus, guisade vós, de Johan Airas de Santiago, a formosura e a indumentária da protagonista assumem um grande relevo como arma de sedução:

Ai mha filha, por Deus, guisade vós que vos veja <e>sse fustan trager voss' amig' e tod' a vosso poder veja vos ben con el estar en cos, ca, se vos vir, sei eu ca morrerá por vós, filha, ca mui ben vos está ${ }^{7}$

Por outro lado ainda, a coita de amor pode fazer com que a mulher recuse embelezar-se, como comprova a seguinte cantiga de Pero Gonçalvez de Portocarreiro:

Par Deus, coitada vivo pois non ven meu amigo; pois non ven, que farei? meus cabelos, con sirgo eu non vos liarei

Pois non ven de Castela non é viv', ai mesela, ou mho deten el rei; mhas toucas da Estela, eu non vos tragerei

\footnotetext{
${ }^{6}$ B 868-869-870/V 454. COHEN, 2003, p.319.

${ }^{7}$ B 599. Idem, p.543.
} 
Pero m' eu leda semelho, non me sei dar conselho; amigas, que farei? en vós, ai meu espelho, eu non me veerei

Estas doas mui belas, el mh-as deu, ai donzelas, non volas negarei; mhas cintas das fivelas, eu non vos cingerei ${ }^{8}$

Perante a ausência do amigo, a mulher enluta-se, renunciando aos prazeres materiais que a indumentária feminina inclui.

A erotização da figura feminina não advém, contudo, dos atributos físicos mencionados nas cantigas de amigo mas do discurso elaborado com os seus signos convencionais mais ou menos explícitos. Alguns elementos da natureza contêm uma carga erótica inegável, como o cervo, a atividade da caça, a fonte, o monte, as barcas, o mar, as ondas, que Mercedes Brea e Pilar Gradín reduzem a três categorias principais: a água (que inclui os elementos de vestuário a ela associados nas composições, como o brial ou as camisas), as aves e as flores.

São sobejamente conhecidas as conotações deste conjunto de vocábulos: o cervo, o mar ou o vento comparecem como símbolos do universo masculino e da fecundidade; a atividade da caça alude ao cortejamento ou dança sexual; o vestuário é um prolongamento da mulher e objeto íntimo; e a flora simboliza a beleza e a renovação fértil. Esta não é uma natura plangens, que podemos considerar excecionalmente presente na cantiga de Meendinho, mas a transposição poética do locus amoenus das Bucólicas e das Geórgicas virgilianas de que a Idade Média se apropriou, uma natureza em comunhão com a renovação da vida e a fecundidade, em que, afinal, o elemento masculino acaba por confirmar a posição de supremacia na sociedade medieval e o domínio sobre a mulher. $\mathrm{O}$ vento, o mar ou o cervo apoderam-se da figura feminina, submetendo-a à sua vontade.

No cancioneiro de amigo de Pero Meogo, o cervo foi utilizado em todas as nove composições. Este símbolo de inequívoca referencialidade fálica remete-nos para o Cântico dos Cânticos, no qual a mulher reivindica: «volta meu amado igual a um gamo/ou a uma cria de gazela/pelo quebrado dos montes» ${ }^{9}$. Aliás, este longo poema poderá ter-se constituído como fonte de inspiração para a prática trovadoresca, isto se considerarmos que além deste elemento também a flora surge com um papel de inegável erotismo e os epítetos de formosa, amiga ou amado são uma constante. Ora se acrescentarmos que em duas das composições de Pero Meogo os «cervos do monte vol $<\mathrm{i}>$ an a auga», temos aqui a metáfora sexual da fusão entre feminino e masculino. Poderíamos ainda considerar que a associação destes elementos - a donzela, o banho e o

\footnotetext{
${ }^{8}$ B 918/V 505. COHEN, 2003, p.321.

${ }^{9}$ Cântico dos Cânticos, 2008, p.35.
} 
cervo - remonta ao mito de Actéon presente nas Metamorfoses ovidianas, que tão frutífero se mostraria depois na poesia de Camões. Porém, se Actéon inadvertidamente surpreendeu Diana no banho e foi transformado em cervo e dilacerado pelos cães, podemos concluir que há uma espécie de moral subjacente ao mito que não se verifica nas cantigas de amigo. De facto, no mito Actéon transforma-se de caçador em caça e é castigado pela sua involuntária ousadia; mas nas cantigas de amigo a personagem masculina interage com a mulher sem consequências punitivas. Ou estaremos equivocados? Ora, considerando que os poemas são delineados pelos trovadores e não pelas protagonistas, verificamos que são as mulheres que se colocam numa situação de isolamento que propicia este tipo de encontros com uma forte carga sensual. Não evidenciará esta descrição de comportamento que, na verdade, é o homem a vítima de tais encantamentos, a presa que sucumbe perante a arte da sedução? E, se os poemas não revelam qualquer sanção, sabemos que nesta época à mulher desvirtuada deveria ser reposta a dignidade com o matrimónio.

Retomando ainda as cantigas de Pero Meogo, há uma composição que menciona que a amiga rompe o «brial» no «bailar», onde também estão presentes o «cervo» e a «fonte». Mais uma vez, dentro do mesmo erotismo metafórico, visualizamos o encontro entre os amantes ante a contrariedade da ludibriada mãe-guardiã. A forma verbal utilizada («rompestes») sugere inequivocamente um ato de desfloração.

Também a protagonista de Estevan Coelho na cantiga Se oj' o meu amigo ${ }^{10}$ refere: «ja filhei o manto». A expressão alude à nudez, para se banhar. Repare-se na expressividade do advérbio de tempo que revela a prontidão do ato e a ansiedade pela chegada do amado. Aliás, segundo Mercedes Brea e Pilar Gradín, «o carácter erótico da inmersión na auga fora censurado pola Igrexa en repetidas ocasións, prohibíndose terminantemente os baños mixtos» ${ }^{11}$.

Outras composições não dependem tanto da utilização do símbolo e «mostram abertamente», ainda que dentro dos limites da convenção (o segredo da identidade da protagonista e, neste caso, enunciadora seria um deles; daí a relativa proteção que um discurso menos eufemístico lhe conferia). Vale a pena transcrever a seguinte cantiga de Johan Airas de Santiago:

O meu amigo, forçado d' amor, pois agora comigo quer viver ũa sazon, se o poder fazer, non dormha ja mentre comigo for, ca daquel tempo que migo guarir atanto perderá quanto dormir

E quen ben qu<is>er seu tempo passar u é con sa senhor, non dorme ren; e meu amigo, pois pera mi ven, non dormha ja mentre migo morar, ca daquel tempo que migo guarir

\footnotetext{
${ }^{10}$ B 721/V 322. COHEN, 2003, p.208.
}

${ }^{11}$ BREA e GRADÍN, 1998, p.126. 
<atanto perderá quanto dormir>

E, se lh' aprouguer de dormir alá

u el é, prazer mh á, per bõa fe,

pero tempo perdud<o> é,

mais per meu grad' aqui non dormirá,

ca daquel <tempo que migo guarir

atanto perderá quanto dormir>

E, despois que s' el<e> de min partir,

Tanto dormha quanto quiser dormir ${ }^{12}$

A figura feminina afirma que o amigo pretende estar com ela durante um período de tempo, se tal for possível. Ela faz questão de impor uma condição ou de deixar um aviso prévio: enquanto ele estiver com ela não dormirá, pois isso seria tempo perdido... E deixa ainda um conselho que se estende aos demais amantes: «E quen ben qu<is>er seu tempo passar/u é con sa senhor, non dorme ren». O remate da cantiga denota até a firmeza da sua decisão: o amigo só poderá descansar quando for embora. Independentemente de um conjunto mais vasto de atividades que os amantes poderiam e procurariam empreender juntos, a cantiga aponta, de modo evidente, para uma união sexual explícita. Se o amigo dormir terá algo a perder; por conseguinte, a argumentação feminina seria fortemente persuasiva. $O$ verbo dormir e a sua negação são, pois, o motor do discurso erotizante. É a mulher quem toma a iniciativa e impõe a sua vontade e regras.

A protagonista de três cantigas de Juião Bolseiro, o poeta noturno, também se queixa da brevidade da noite quando está com o amigo e de que quando está só as noites se alongam. Na cantiga Sen meu amigo manh' eu senlheira diz: «Quand' eu com meu amigo dormia,/ a noite non durava nulha ren,/ e ora dur' a noit' e vai e ven»-sugerindo a insónia noturna. Da noite d'eire poderan fazer e Aquestas noites tan longas que Deus fez en grave dia abordam a mesma temática. Assim, a convocação do cenário noturno e do tempo psicológico que evoca a presença ou a ausência do amigo implicam também, e inegavelmente, uma sugestividade erótica.

Em algumas cantigas a mulher aparenta uma ingenuidade que se apercebe ser forjada. A título de exemplo veja-se a cantiga Diz meu amigo que lhi faça ben, de Johan Servando:

Diz meu amigo que lhi faça ben, mais non mi diz o ben que quer de $m i<n>$; eu por ben tenho de que lh' aqui vin polo veer, mais el assi non ten, mais, se soubess' eu qual ben el querria aver de mi, assi lho guisaria ${ }^{13}$

${ }_{12} B$ 1033/V 623. COHEN, 2003, p.567.

${ }^{13} B$ 1152/V 745. COHEN, 2003, p.380. 
A figura feminina considera que o facto de se encontrar com o amante é por si só prova de amor suficiente. Todavia, isso não corresponderia às expetativas do amigo, que «assi non ten» mas também não revela «o ben que quer». Fazer bem assume, à semelhança do que igualmente ocorre noutras composições em que se menciona esta expressão, uma explícita conotação de cariz erótico. A mera presença física não satisfaz o desejo que sente pela amada e ele não pode solicitar abertamente o que pretende, quer porque o código de honra o impede, quer porque perante a ingenuidade aparente da mulher, que mesmo não sabendo do que se trata diz que «lho guisaria», receia uma recusa.

A composição Pero vos ides, amigo, de Johan Perez d' Avoin, é também exemplificativa dessa aceção: nas palavras da mulher o amado parte «por non fazer eu quanto faz/molher por om' a que quer ben». E a protagonista da composição seguinte de Johan Soarez Coelho diz:

Ca eu nunca con nulh' ome falei, tanto me non valha Nostro Senhor, des que naci, nen ar foi sabedor de tal fala nen a fiz nen a sei, e pesa mi que m' enviou dizer <que lhi faça o que non sei fazer $>^{14}$

Em face do exposto, bem se poderia, pois, reconhecer que nas cantigas de amigo é o homem quem solicita algo proibido à mulher e é ela o elemento mais ponderado, porquanto raramente acede às suas pretensões, mesmo que contrariada. Gonçalo Eanes do Vinhal põe em cena a amiga que diz que o amigo morre «por aquel ben que nunca pode aver/mais non quer'eu por el meu mal fazer» ${ }^{15}$; em Estevan Travanca a protagonista afirma que foi contra a sua vontade que não fez «por el quant' eu quisera enton» ${ }^{16}$; em Guilhade a mulher diz que «de pran non sõo tan louca/ que ja esse preito faça» ${ }^{17}$, noutras duas composições reforça a ideia de que apesar de já ter ofertado a cinta a seu amigo ele lhe demandava outra «folia» ou mesmo «torpidade» e noutra cantiga o amigo solicita-lhe um «preito maior»; a amiga de Pero Mafaldo diz que fará bem ao amigo mas não «quant' el quiser»; em Johan Airas de Santiago a amiga assegura que fará bem desde «que seja vosso ben e non meu mal» e noutra das suas cantigas avança mesmo que se fizer bem ao amigo «log' el querrá que lhi faça melhor». Ou seja, de acordo com Mercedes Brea e Pilar Gradín:

O erotismo encóbrese nalguns textos nunha serie de vocábulos que funcionam como metáforas. É o caso de preito, folia, torpidade, al na producción de Johan Garcia de Guilhade, na que as mencionadas palabras son empregadas conscientemente de maneira eufemística (...). Pero, sen dúbida, son os sintagmas

\footnotetext{
${ }^{14}$ B 686/V 288. Idem, p.171.

${ }^{15}$ B 711/V 312. Idem, p.197.

${ }^{16}$ B 724/V 325. Idem, p.212.

${ }^{17}$ B 744/V 346. Idem, p.233.
} 
fazer-aver ben / fazer prazer os que recollen o maior índice de frecuência do uso metafórico. (BREA e GRADÍN, 1998, p.102-103).

Estas figuras femininas mostram-se todavia bem cientes dos perigos que correm nos encontros furtivos e ao mesmo tempo do seu poder de encantamento. Alguns dos amigos chegariam a vangloriar-se do bem que elas na verdade se recusaram a fazer, aspeto que é em muitos casos esclarecido, como em Johan Airas de Santiago: «ca mui ben sei eu que non fezestes/ o meio de quanto dissestes» ${ }^{18}$; e o poder encantatório não é menos omitido numa cantiga de D. Dinis: «Ca, se cuidasse de mi ben aver,/ant'el queria viver ca morrer» ${ }^{19}$.

O erotismo da figura feminina no cancioneiro de amigo pode ser também associado a uma certa frieza ou altivez, como se de uma sensação de poder tirânico se pudesse tratar. Na cantiga Morr' o meu amigo d' amor, de Johan Garcia de Guilhade, a protagonista diz não se incomodar se o amigo morrer por ela («e a mi praz de coraçon /por veer se morre, se non»).

Terminamos este elenco exemplificativo do erotismo que enleia a mulher medieval do cancioneiro de amigo com a cantiga $O$ meu amigo, que <eu> sempr' amei, de Johan Vasquiz de Talaveira:

O meu amigo, que $<$ eu $>$ sempr' amei
d<el>o primeiro dia que o vi,
ouv' el un dia queixume de mi,
non sei por que, mais logo lh' eu guisei
que lhi fiz de mi queixume perder,
sei m' eu com' e non o quero dizer
$(\ldots)$
E quen esto non souber entender
nunca én mais per mi pode saber ${ }^{20}$

Perante o amigo queixoso, a mulher arranja uma maneira de resolver a situação. O plano parece resultar («lhi fiz de mi queixume perder»). Porém, ela não revela o seu segredo («sei m' eu com' e non o quero dizer»). O mistério de que se reveste a solução apresentada pela amiga é, ao mesmo tempo, e segundo ela afirma, do conhecimento comum («E quen esto non souber entender/nunca én mais per mi pode saber»), ou seja, numa paráfrase do ditado popular «para bom entendedor, meia palavra basta». Neste caso, é o desenvolvimento do discurso que induz e gera o erotismo: no início há um queixume; depois uma solução; segue-se a discrição da medida tomada; e, por fim, o reconhecimento de que, apesar de tudo, se trata de algo de alcance geral.

Podemos, então, concluir que no cancioneiro de amigo há uma nítida dualidade entre a mulher terrena e a mulher idealizada (retrato verosímil que se divide entre o pudor, a inocência e os assomos de luxúria): por um lado, o desejo carnal leva os autores a construir um cenário ficcional que corresponda aos seus devaneios, como se a

\footnotetext{
${ }^{18}$ B 1026/V 616. COHEN, 2003, p.559.

${ }^{19}$ B 580/V 183. Idem, p.615.

${ }^{20}$ B 789/V 373. Idem, p.257.
} 
poesia exorcizasse, de facto, a tentação; esta é uma atitude voyeurista; por outro, não é menos verdade que os compositores parecem indecisos entre a concretização, que reclama para si o conhecimento dos desejos íntimos femininos e a consequente submissão ao amor ou a inclusão numa sociedade constrangida no espartilho da recriminação católica do prazer.

Refere Ernst Curtius acerca da concepção do Amor na Baixa Idade Média:

Notamos, pois, nos meados do século XII, quatro diferentes atitudes para com Eros: o ideal estético amaldiçoa-o, a devassidão rebaixa-o, a mística espiritualiza$\mathrm{o}$, a gnose consagra-o. O contemptus mundi elimina-o, mas a universitas mundi $\mathrm{o}$ adota. (CURTIUS, 1957, p.127).

O amor na Idade Média é, pois, literariamente retratado como uma maldição que se apodera dos homens. Apenas o amor espiritual é pacificamente aceite. A mulher terrena é o agente da destruição que rememora ainda Eva, por isso a tradição eclesiástica recomenda a abstinência. Eva foi a primeira a estabelecer uma relação com o Outro e isso resultou em consequências catastróficas para as gerações vindouras. Não há, portanto, uma consensualidade no que se refere às relações amorosas. Se por um lado a mulher é um objecto precioso e até sagrado, por outro é ela a sedutora serpente, a reconhecida «fada na fonte» do romance arturiano ou ainda a Fénix, urdidora de enganos, do Horto do Esposo.

Todavia, a mulher presente no cancioneiro de amigo parece querer trilhar novos caminhos inspirando-se na figura de Maria Madalena. Trata-se de um meio-termo e um aviso de prudência: a mulher pode ser tomada e desejada (com a contenção que a época exige) e ainda assim haver uma hipótese de redenção para os amantes.

As composições retratam na realidade uma hegemonia masculina que se apropria inclusivamente da voz feminina para exteriorizar os seus anseios. O alargamento do interesse pela canção trovadoresca no ambiente das cortes régias e senhoriais está intimamente ligado às transformações sociais que então se operavam: a tentativa de evitar que o património de uma família se dissipasse em sucessivas partilhas tornava o filho primogénito detentor de quase toda a herança; em consequência, os outros descendentes teriam que se resignar à vassalagem ou procurar a sua própria fortuna. A par do desenvolvimento deste sistema de linhagens, a mulher opta frequentemente por uma vida de ascetismo ou pelo recolhimento monasterial que a afaste de um casamento indesejado. Esta tendência coloca a figura feminina no centro das atenções, como elemento imprescindível e ao qual cabia o papel de assegurar a descendência nobre.

É, pois, por detrás do palco que se disputa o protagonismo pelo poder: a ausência da mulher enquanto autora de textos medievais comprova o seu difícil acesso à palavra pública; no entanto, ao comparecer como personagem principal da poesia trovadoresca, quer nas cantigas de amigo, como suposta enunciadora dos poemas, quer nas cantigas de amor, como receptáculo dos afetos do autor, a mulher parece ter um papel decisivo na sociedade e na literatura. 


\section{Referências bibliográficas}

BREA, Mercedes e LORENZO GRADÍN, Pilar (1998), A cantiga de amigo, Vigo, Edicións Xerais de Galicia.

Cântico dos Cânticos (2008), tradução de José Tolentino de Mendonça, Lisboa, Editores Independentes.

COHEN, Rip (Ed.) (2003), 500 Cantigas d'Amigo, edição crítica, Porto, Campo das Letras.

CURTIUS, Ernst Robert (1957), Literatura Européia e Idade Média Latina, tradução de Teodoro Cabral, Rio de Janeiro, Instituto Nacional do Livro.

DUBY, Georges e PERROT, Michelle (1990), História das mulheres. A Idade Média, Porto, Afrontamento.

LE GOFF, Jacques (1993), O nascimento do Purgatório, Lisboa, Estampa.

MATtoso, José (dir.) (2010), História da vida privada em Portugal. A Idade Média, Porto, Círculo de Leitores. 